\title{
ENSAYOS
}

\section{Espacios educativos "otros" y saberes ecológicos: Ferias de intercambio y consumo colaborativo en Chile}

\author{
"Other" educative space and ecological knowledge: \\ Exchange and collaborative consumption trade fairs in Chile
}

\author{
Constanza Yáñez-Duamante, Iván Oliva-Figueroa , \\ Gabriela Catalán-Verdugo ${ }^{c}$, Alberto Moreno-Doña ${ }^{d}$ \\ ${ }^{a}$ Escuela de Periodismo, Universidad Católica del Norte. \\ Correo electrónico: cyanezduamante@ucn.cl. \\ ${ }^{\text {b }}$ Instituto de Ciencias de la Educación, Universidad Austral de Chile. \\ Correo electrónico: ivanoliva@uach.cl

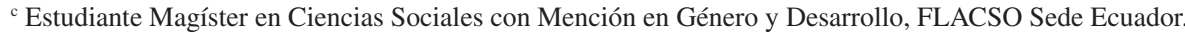 \\ Correo electrónico: g.catalanverdugo@gmail.com

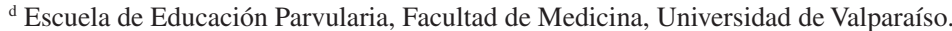 \\ Correo electrónico: alberto.moreno@uv.cl
}

\section{RESUMEN}

La ambición instalada como presente inalterable de modelo económico, impone regulaciones que privatizan la vida y sus saberes. Del patrimonio tangible e intangible de los pueblos queda la resistencia decolonial contrapuesta a los intereses del capital. De ahí nuestro interés en el trueque, como práctica sociopolítica resignificante de auto-existencia y relaciones sociales recíprocas. Este artículo discute la relacionalidad teoría <-> praxis del trueque, como espacio educativo 'otro', develando nuevas formas de interpretar la realidad y transformar experiencias educativas, fisurando estructuras sociales en base a cosmoexistencias ancestrales, como es el caso de "AntofaTrueke" en la ciudad de Antofagasta, al norte de Chile y de la "Red Trueke" Valdivia, al sur del país, gestada en un movimiento estudiantil y ambiental ciudadano.

Palabras Clave: Trueque/intercambio, colonialidad, decolonialidad, reapropiación social, desarrollo humano, saberes ecológicos.

\section{ABSTRACT}

The ambition set up as the unchanging present of the economic model, imposes regulations that privatize life and knowledge. However, as part of the tangible and intangible heritage of the peoples remains the decolonial resistance clashing against the interests of the capital. Thereupon, our interest in the barter as a sociopolitical practice which re-signifies the self-existence and the reciprocal social relationships.

This article discusses the theory <-> practice of bartering as an "other" educative space, unveiling new ways of interpreting reality and transforming educational experiences, cleavingsocial structures based on ancestral cosmoexistences; as it is the case of "AntofaTrueke" in Antofagasta city, to the North of the country, and the "Valdivian Barter Network," to the South of the country, which was created under the wing of a student and environmental civic movement

Key words: Barter/exchange, coloniality, decoloniality, social reappropriation, human development, ecological knowledge. 


\section{INTRODUCCIÓN}

El trueque integra cosmovisiones centradas en relaciones humanas armónicas hacia los entornos naturales. Esta práctica ancestral se encuentra presente a través de ferias de intercambio, cuya praxis continúa desarrollándose en innumerables contextos, rurales y urbanos, re-existiendo también como herramienta de transformación social y resistencia ante la competencia estéril, el lucro y la especulación económica. Se hace posible otra oikonomía $^{1}$, sustentada en valores solidarios, cooperativos y más justos, poniendo a disposición productos, servicios, saberes y otras múltiples expresiones, en los que la moneda de cambio es el diálogo y no el dinero. Otras formas de convivir en el mundo son posibles, por ello se visibilizan experiencias de trueque, presentando y reflexionando en esta ocasión valiosos trabajos desarrollados en el norte y sur de Chile. Dos experiencias que se co-inspiran bajo los lemas ;Te lo cambio! y ;Sin Plata Resulta!

Como espacio comunicativo y educativo 'otro', el trueque (nos) permite reaprender desde las fisuras de ciertas estructuras sociales, develando nuevas formas de interpretar la realidad; además de transformar experiencias educativas en el ámbito de la comunicación, como es el caso de "AntofaTrueke" en la ciudad de Antofagasta, al norte de Chile; y desde el devenir de un movimiento estudiantil y ambiental ciudadano en Valdivia, al sur del país. Estas instancias, entre otros aspectos, potencian expresiones artísticas y culturales locales, colaborando en el fortalecimiento del patrimonio e identidad regional de sus habitantes. La proyección en común está dirigida a encauzar el trueque como práctica cotidiana de intercambio y consumo colaborativo, acorde a un desarrollo humano consciente, habilitando además saberes ecológicos y espacios autodependientes, solidarios y de reapropiación social.

La voluntad insurgente de sujetos colectivos (Yáñez-Duamante, Browne y Music, 2016), reunidos en la utopía posible de decolonizar la vida y su cosmoexistencia, no tiene un único camino, -no es una receta-, ni una metodología a la usanza académica; el rebrote de saberes ecológicos ancestrales es en sí una fuerza vital que trasciende la lógica de la razón moderna; parece ser un compromiso con la vida e inherente a ella; un pulso en direcciones diversas que arremete una y otra vez para reclamar lo que le es propio.

\section{ANTECEDENTES DE AMBOS PROYECTOS DE INTERCAMBIO}

\subsection{FERIA DE INTERCAMBIO Y CONSUMO COLABORATIVO: ANTOFATRUEKE ¡TE LO CAMBIO!}

Esta iniciativa lleva seis años de realización en el norte de Chile. Surge el año 2011 como proyecto de docencia y extensión, en el marco de la cátedra de "Diseño de Proyectos y Eventos" de la Escuela de Periodismo de la Universidad Católica del Norte. Se inicia como una instancia para resolver en equipos de trabajo, problemas vinculados a proyectos y eventos comunicacionales, y dominar estrategias creativas de comunicación y gestión. Tras profundizar en elementos teóricos, se plantea a estudiantes de tercer año de Periodismo la

\footnotetext{
"Oikonomia. (del griego) del sustantivo oikos y del verbo nemo. Este segundo término significa distribuir o administrar" "Mientras que el primer vocablo ha sido entendido como concepto que engloba casa, propiedades y familia, es un ente constituido para la producción/reproducción de descendientes, así como de los soportes materiales e inmateriales que garanticen el sustento de esta regeneración. Oikos es una entidad económica; la unidad principal de producción y consumo. La oikonomia refería entonces a la administración de esta célula social básica” (Mirón, 2004, p.61-64).
} 
materialización de un evento de carácter social, en que puedan desplegar enfoques críticos en torno a estrategias de comunicación y gestión: para tal efecto, una feria de intercambio abierta a la comunidad antofagastina. La iniciativa se co-inspira en el trabajo desarrollado al sur de Chile, por la "Red Trueke" en Valdivia.

Dado el contexto económico que mueve a una ciudad minera como Antofagasta, se agrega complejidad solicitando a los y las estudiantes que realicen la feria, sin presencia de dinero ni donativos gestionados a través de empresas mineras.

La actividad abierta a la comunidad contiene además elementos de contingencia social. En sus ya seis años de trabajo, estas ferias de trueque han incluido actividades que revitalizan la diversidad cultural desde la interculturalidad crítica (Walsh, 2010), en momentos en que emergía un profundo malestar social en relación con ciudadanos migrantes en Antofagasta - principalmente colombianos ${ }^{2}$. A la vez, también se ha promovido la sostenibilidad, redistribución y comercio justo, reconociendo y socializando la urgencia de su reivindicación en la ciudad.

"AntofaTrueke" posibilita espacios socioculturales de intercambio, apropiación y reapropiación por parte de la comunidad local antofagastina. En esta experiencia socioeducativa, desde la enseñanza y el aprendizaje como praxis, es posible reconocer, al menos, las siguientes tres dimensiones:

i. Formativa experiencial situada: la instancia como una plataforma donde jóvenes desarrollan capacidades creativas, de gestión, organización, comunicación y trabajo en equipo, mediante el diseño y materialización de un proyecto social, para este caso, las ferias de consumo colaborativo; se revitaliza así una práctica y saber ancestral disminuido ante el aparente auge económico en la región.

ii. Sociocultural: las ferias de trueque como consumo colaborativo activan un espacio social de intercambio de bienes, servicios y saberes a toda la comunidad antofagastina, sin la mediación del dinero, son la interacción, el diálogo y la confianza entre las/os participantes las únicas monedas de cambio presentes.

iii. Actitudinal: bien común, interculturalidad crítica, diversidad cultural, solidaridad, reciprocidad y desarrollo sostenible han sido actitudes promovidas en, por y desde las/os estudiantes, lo que fomenta a su vez la propia vocación social, traducida en una oportunidad formativa con conductas solidarias hacia su entorno.

"AntofaTrueke", como innovación metodológica, asocia la planificación e implementación de estrategias de formación, acordes al enfoque de un proyecto educativo universitario, por lo cual ha recibido el Premio de Innovación al Mejoramiento de Docencia de Pregrado UCN (2014). Los seis años de trabajo han apoyado sus metodologías en el Aprendizaje Basado en Problemas (ABP), con la finalidad de que los estudiantes adquieran los conocimientos requeridos en el curso y los apliquen en soluciones reales, como estrategia eficaz y flexible para mejorar la calidad del aprendizaje universitario en aspectos diversos; y el Aprendizaje Más (+) Servicio, enfatiza no solo en la calidad del aprendizaje sino también en las relaciones socioculturales a partir del mismo.

En ese entonces comenzaron a realizarse inéditas marchas en rechazo a migrantes colombianos en Antofagasta, en las cuales se exigía a las autoridades la expulsión de los mismos fuera de territorio chileno. Referencia en material de apoyo del curso electivo "Pensamiento Crítico y Comunicación" de la Escuela de Periodismo (2013). https://www.youtube.com/ watch?v=B230sVZAmKg 
En "AntofaTrueke" han colaborado diversas agrupaciones medioambientales como "Colibrí Eco-social", "Recihuerteros", "Este Polvo te Mata" y "Recicla UCN"; también grupos de danza urbana, agrupaciones migrantes, comunidad espiritual Vaishnava, tambos andinos y diversos cantautores locales. A lo anterior se suman instancias de poesía, cuentacuentos y susurradores. Actualmente esta feria es reconocida como una instancia familiar, por lo que las edades efectivas de los y las trocadoras(es) va desde los cuatro años hasta alrededor de los 80 años sin exclusión.

\subsection{FERIAS DE TRUEQUE EN VALDIVIA}

La "Red Trueke" es una organización valdiviana de carácter comunitario con personalidad jurídica reciente, que desde hace 9 años organiza ferias de trueque en el sur de Chile. La iniciativa parte el año 2007 como un proyecto de extensión desarrollado por estudiantes de la Universidad Austral de Chile, con el cual implican a la ciudad y vinculan experiencias brasileñas de intercambio en Curitiba y Río Sagrado. Las primeras ferias de trueque se organizaron en las localidades de Tralcao, San Ignacio, Los Molinos, diferentes barrios urbanos y la antigua estación de trenes de la ciudad de Valdivia.

Las ferias de trueque tienen una extensa trayectoria en la Región de Los Ríos, parten como eventos autogestionados y dirigidos a localidades rurales de la comuna de Valdivia, para luego continuar con la realización por cinco años consecutivos de la "Estación Trueke". Sumado a lo anterior, estas ferias se inspiran en experiencias como la Red Global de Trueque en Brasil, Colombia y Argentina, y se convierten en un espacio abierto de encuentro e interacción entre distintos actores sociales (estudiantes, ciudadanos/as, autoridades, líderes locales, artistas, investigadores/as, jóvenes, adultos, niños y niñas, etc.) a nivel regional, nacional e internacional.

En el transcurso de las movilizaciones estudiantiles del año 2011, se realizaron dos ferias de trueque en apoyo al movimiento estudiantil en establecimientos secundarios "en toma". El trueque como práctica de intercambio vuelve a estar vinculado a un proceso de transformación social y a intentar ser una herramienta para la misma, mediante la cual las/ os estudiantes pueden exponer sus demandas a la ciudadanía en general.

Durante el año 2013 e inicios de 2014 se realizaron diversas ferias, como la feria de trueque de verano realizada en el torreón de la "Escuela México" de la ciudad; la feria de trueque de invierno realizada en la "Escuela de Arquitectura" de la Universidad Austral de Chile; la feria de trueque en el "Parque Harnecker" que tuvo un giro hacia la educación ambiental y el uso responsable de áreas verdes urbanas, y en la cual además la "cocina truekuera" sirvió como espacio de recopilación de libros para la "Escuela La Aguada" en $\mathrm{Corral}^{3}$.

En enero de 2014 se llevó a cabo la feria de trueque "Intercambio de Servicios y Saberes", que privilegiaba conocimientos y oficios para potenciar otras posibilidades de trueque. A mediados y fines de 2015 se realizaron dos nuevas jornadas de trueque, centradas en servicios y saberes, que ampliaban las posibilidades de intercambio y creatividad. Luego de dos años de receso, en 2018 se llevaron a cabo ferias de trueque de productos hechos a mano, servicios y saberes. Estas instancias tenían el objetivo de reflexionar sobre intercambio responsable. Además, se incorporó como elemento central las semillas, plantas

Comuna perteneciente a la provincia de Valdivia en la Región de Los Ríos. 
y saberes, que colocabamn a disposición tanto elementos tangibles como intangibles sobre la biodiversidad, flora y naturaleza de la Selva Valdiviana.

\section{INTERCAMBIO Y COLONIALIDAD}

El intercambio de productos y saberes es casi irrastreable, pues es parte de las primeras formas de coexistir de las comunidades humanas. Cuando Chile no era ni siquiera un proyecto lejano en el lado sur de Latinoamérica, la nación Mapuche hacía Txafkintun. Etimológicamente esta palabra se compone de Txaf, que significa nosotros/as dos, uno/a al lado del otro/a; y de kintun, que refiere al agrado de buscar con la mirada y encontrar algo (Ñanculef, 2011). Es así como la palabra txafkintun, encarna la mirada de los(as) dos, que es una mirada afectiva que nutre a uno(a) y a otro(a). Txafkintun no era un intercambio económico, sino una relación y acción humana, que toma un ribete económico con la llegada del colonialismo español al territorio. Desde una dimensión de buen vivir, bienes materiales y conceptuales solo pueden devenir de prácticas sociales y formas de vida ancestrales, que resisten a otras formas de vida basadas en la depredación ambiental (Palencia, Zamora, Salazar y Mendizábal, 2014).

Con la intencionalidad de alejarnos de prácticas de consumo que, directamente, influyen el malestar de la ciudadanía (consciente o insconcientemente), el trueque nos invita a mirar(nos) desde un imaginario histórico anticapitalista; y es aquí donde el buen vivir, como forma de ser y estar en el mundo que surge, nos hace mucho sentido como capacidad de legitimar subjetividades diversas focalizándonos en la reciprocidad y en una diversidad de saberes que liberan de la explotación y dominación: formas de ser y estar centradas en la solidaridad entre las personas y la naturaleza. Es la forma de poder vencer el carácter inmediato del capitalismo tardío. El "Buen vivir" (Marañón, 2014), permea la lógica desde la que se proponen las ferias de trueque. Asumimos la complejidad que entraña definir el "buen vivir", pues no es ni una tesis ni un concepto (Acosta, 2016), es una experiencia contextualizada a cada una de las formas de ser y estar de los pueblos originarios de nuestra América. El Buen Vivir, desde los pueblos americanos, asume que no puede ser la economía la respuesta única al bien ser y bien estar de los pueblos, sino que el vivir en plenitud está determinado por una relación con uno mismo, con los demás y con la existencia en general (Huanacuni, 2010). Al capitalismo no le preocupa, genuinamente, lo que se intercambia, sino el valor comercial de los productos que forman parte de dicho intercambio. Es decir, su gran preocupación gira en torno a la existencia de consumo. Por ello es capaz de ofrecer (vender) algo y, a la vez, vendernos otra cosa para disminuir los daños provocados por la primera venta.

El colonialismo como hecho histórico, provocó la transformación sociocultural del continente 'americano', marcado por la imposición del occidentalismo como sistema de vida por parte de ciertas metrópolis hacia sus colonias; ejerciendo dominación social, cultural, del lenguaje, la religión, la política, el medio ambiente, la economía, los saberes, los imaginarios, los propios cuerpos, entre muchos otros. "La primera colonización capitalista fue la de las Américas, conquistadas por españoles, portugueses, ingleses y franceses. En sus colonias americanas, las clases dirigentes (...) instauraron sistemas económicos y sociales particulares, concebidos al servicio de la acumulación en los centros dominantes de la época" (Fanon, 2009, p. 7). 
El siglo XIX dio paso al proceso de independencia que dejaba "atrás" la época colonial. Sin embargo, los recursos naturales al sur del continente continuaron centrando la atención de grupos económicos -tanto internos (a través del propio aparato estatal, por ejemplo) como externos al territorio- que promovían nuevas formas de dominación -aún vigentesen apariencia menos violenta y estratégicamente sutil-paternalista; la colonialidad, capaz de intervenir en las formas de comprender el mundo y en el proyecto de vida humana.

Aquella configuración de un único mundo dominado por Europa -que logra establecer el capitalismo mundial- actualmente enfrenta su crisis más severa: la explotación insostenible de 'recursos naturales' y la incompatibilidad de resguardar con ello la existencia y el bienestar de todas las formas de vida sobre el planeta. La colonialidad hace eco de este problema y lo profundiza, marginando aquellos sistemas de vida considerados como 'subalternos', "porque América Latina fue el espacio original y el tiempo inaugural de un nuevo patrón de poder, históricamente específico, cuya colonialidad es su característica, su inextricable rasgo fundacional e inherente desde hace poco más de quinientos años, hasta hoy" (Quijano, 2009, s.p.) ${ }^{4}$.

Desde esta base, se han modificado estilos de vida y prácticas culturales, desvalorizando a su vez las sabidurías ancestrales. En esta recuperación trabaja la decolonialidad como proyecto de resistencia, que apunta no solo a la transformación de dimensiones estructurales del poder y sus aparatos de dominación, como proponía la decolonización, sino también al enfrentamiento de la colonialidad del saber, del ser y de la existencia misma; en un intento por "la recuperación de la humanidad y de la dignidad negadas por la colonialidad" (Guerrero, 2010, p. 84).

A la vez, la descentralización de estos procesos sociopolíticos y económicos conlleva la invisibilización de los sustratos ideológicos y paradigmáticos que están a la base de su amplia legitimación social, aletargando de este modo los sustratos de emergencia para nuevas expresiones de resistencia colectiva. En contraste y como punto de inflexión, Palencia, Zamora, Salazar y Mendizábal sostienen:

Las culturas mercantiles suponen procesos amplios de intercambio fluido, de convergencias entre modos de explotación, formas de dominación y construcción de desarrollo desiguales. Pero no son estáticas, pues sus formas de organización social no se orientan mediante ideologías impenetrables, ni se corresponden a grupos de poder incontestables situados en un lugar inalcanzable. Se trata de procesos sociales, y como tales, posibles de ser transformados, de ser reconfigurados. Y es necesario exponer cómo a contrapelo de estos procesos de despojo y formación de periferias hay sujetos emergentes, que contestan desde sus prácticas sociales, y sus ideologías colectivas, ante las relaciones sociales que se les intenta imponer (Palencia, Zamora, Salazar y Mendizábal, 2014, p. 186).

Desde esta base, el txafkintun y las ferias de intercambio que aquí se abordan son intentos esperanzadores por recuperar espacios de humanidad en medio del caos económico innegable que (nos) desborda y devora. 


\section{REAPROPIACIÓN SOCIAL A 'ESCALA HUMANA'}

La apropiación social no es la adaptación sino el dominio de un espacio dotado de contexto sociocultural e histórico, en un proceso dinámico en el cual las personas se hacen a sí mismas mediante sus propias acciones (Vidal y Pol, 2005). Neüman (2008) alberga en la apropiación social, la posibilidad de comprender la doble articulación de resistencia y negociación que caracteriza a los mundos de vida de las poblaciones latinoamericanas desde la época colonial.

En este contexto, aquello considerado como universal y verdadero es en realidad ajeno y, por ello, demanda apropiación. Corresponde a los grupos sociales acordar los términos de lo que han decidido como propio. En la búsqueda común de este horizonte, diversos pueblos de Latinoamérica continúan el proyecto de resistencia negociada con la 'modernidad'. Quijano (2012) sostiene al respecto:

la resistencia tiende a desarrollarse como un modo de producción de un nuevo sentido de la existencia social, de la vida misma, precisamente porque la vasta población implicada percibe, con intensidad creciente, que lo que está en juego ahora no es solo su pobreza, como su sempiterna experiencia, sino, nada menos que su propia sobrevivencia (Quijano 2012, p. 84).

De este modo, la apropiación social demanda "que las leyes y teorías de la ciencia no sean universales, la posibilidad de construir conocimiento desde lo local, no generalizable al resto de las situaciones parecidas, y desde donde el devenir histórico es fundamental" (Neüman, 2008, p. 6). La fuerza decolonial de la apropiación social afecta directamente a la economía, las dimensiones estructurales del poder y sus aparatos de dominación, y más a largo plazo también a la producción de conocimiento como sabiduría insurgente. Invita a superar la dimensión antropocéntrica con que nos hemos venido relacionando, a despertar y concientizar la fragilidad humana y del planeta, así como a interrogar la existencia y su devenir en el mundo de la vida.

La apropiación social que surge en contexto de 'desarrollo a escala humana' (MaxNeef, 1998), demanda un proyecto de autodependencia, articulación y organización real de las personas, en una nueva forma de interpretar 'la realidad' y en un esfuerzo de apertura intelectual fecunda. Para el caso específico de los proyectos de intercambio y consumo colaborativo co-inspirados entre Antofagasta y Valdivia, referiremos comprenderlos en contexto de reapropiación social, dado que la práctica ancestral del trueque convoca la revitalización de dicho espacio y sus múltiples dinámicas resignificadas actualmente en y para diversos contextos.

Tras el diálogo profundo de experiencias de intercambio en Brasil y Argentina, deviene el proyecto de la "Red Trueke" Valdivia, la cual inspira a su vez las Ferias de Intercambio y Consumo Colaborativo "AntofaTrueke", que luego permea espacios de trueque en las comunas de Arica y Fresia en Chile. La reapropiación social que emerge en estos espacios sinérgicos de intercambio, no solo enfatiza en la satisfacción de necesidades humanas en sentido amplio, sino también en una cosmovisión ecológica de desarrollo que trasciende la racionalidad económica convencional y compromete al ser humano.

"No se trata de relacionar necesidades solamente con bienes y servicios que presuntamente las satisfacen, sino de relacionarlas además con prácticas sociales, formas 
de organización, modelos políticos y valores que repercuten sobre las formas en que se expresan las necesidades" (Max-Neef, 1998, p. 51). En este sentido, las experiencias de intercambio de Antofagasta y Valdivia promueven el desembarco de la carrera productivista al servicio de artefactos, revindicando el intercambio de saberes en torno a problemáticas antropo-sociales situadas. Por ello la reapropiación social de estos espacios, en tanto fisura a la colonialidad, logra palpar la 'resistencia negociada' que expone Neüman (2008). Así, se fisura la lógica competitiva al interior de un modelo económico expansivo universalista, que en lo particular agrieta desde la educación de formación superior terciaria, en las universidades Católica del Norte y Austral de Chile, hasta las formas de (auto)gestión y organización -en base a una ética solidaria- entre quienes reapropiaron dichos espacios de intercambio; restituyendo de paso el germen de la conversación abierta y profunda (Maturana y Dávila, 2015), la creatividad social, la participación popular y la autodependencia.

\section{COLONIZACIÓN EPISTEMOLÓGICA: PUNTO DE PARTIDA PARA UN ESPACIO EDUCATIVO "OTRO"}

En este sentido las ferias de intercambio, resisten a la perspectiva epistemológica moderna y occidentalizada, que tiene su origen en los procecesos de colonización a partir de los cuales modernidad y capitalismo emergen como las únicas formas posibles de habitar el mundo (Dussel, 2015), dando lugar a formas de aprender caracterizadas fundamentalmente por la dicotomía, linealidad, causalidad, el deber ser y la generación de respuestas medibles y observables (Calvo, 2016): una epistemología moderna y eurocéntrica construida por hombres, europeos-norteamericanos, heterosexuales, capitalistas y patriarcales (Dussel, 2015; Grosfoguel, 2013). El orden lineal -impuesto en la forma de entender el conocer, que no siempre educativo- suele excluir otras posibilidades de relación, de comportamientos $\mathrm{y}$, en última instancia, de aprendizajes. Todo el que se aleje de esta lógica epistemológica queda relegado, al menos simbólicamente, a tener que parecerse a ese sujeto universal para el que la educación formal trabaja (Grosfoguel 2013). Todos esos que se alejan estarían circulando por los márgenes de la institucion educativa formal, por ese lugar que Fanon (1961) llama la 'zona del no ser', que De Sousa (2013) denomina 'el lugar existente por debajo de la línea abismal' y que Freire (1975) conceptualiza como 'los oprimidos'. Un espacio-tiempo que no reconoce la humanidad de los sujetos 'diferentes'. Esta epistemología que homogeneiza no ha permitido reconocer que el aprendizaje emerge en lugares y tiempos muy diversos.

Por no atender a la realidad particular de los sujetos que aprenden, terminamos violentándolos para que se ajusten al patrón que creemos legítimo desde las teorías pedagógicas que se imponen; a la vez que negamos la subjetividad de esos mismos sujetos. La 'zona del no ser' nos invita a rescatar el mundo de la vida que emerge en el aprendizaje, pues este no es una condición objetiva y tangible sino una experiencia encarnada histórica y socioculturalmente (Meleau-Ponty, 1945; Varela, Thompson y Rosch, 2011).

Todo ello se hace en nombre de un conocimiento anclado aun en una lógica cartesiana, dualista en términos de civilización y barbarie (Dussel, 2015) y en la que los que viven en situación de pobreza, los otros géneros y las etnias son vistos como una forma de subhumanidad, "una forma degradada de ser que combina cinco formas de degradación: ser ignorante, inferior, atrasado, vernáculo o folklórico y perezoso e improductivo" (De 
Sousa, 2014, s.p.). Desde esta base, todo aprendizaje que opera lejos y fuera de lo formal, como es el caso del aprendizaje encarnado en las ferias de trueque, suele ser reducido e invisibilizado en términos educativos.

Esta situación, con toda la complejidad que ello implica, es causa de un hacer científico en educación que ha generado una profunda dicotomía entre un discurso lleno de conceptos ligados a una educación transformadora (democracia, participación, transformación, justicia...) y unas prácticas atomizadas, superficiales y seudoparticipativas desde las que no se logra contextualizar la complejidad del aprendizaje, más centrado en el control que en la propensión a la transformación de las realidades que operan en espacios educativos otros.

En el contexto del despliegue de las ferias de intercambio, entendemos por espacios educativos "otros" todas aquellas propuestas educativas alejadas de las instituciones educativas modernas occidentalocéntricas -educación formal- en las que la linealidad, el orden y el control son las grandes categorías desde las que explicar el aprendizaje. El aprendizaje en estos espacios educativos "otros" estaría caracterizado por aquello que es propio de la experiencia del vivir, aquello que es encarnado en la cotidianeidad de los sujetos; y esas experiencias vividas en esos espacios educativos, estarían caracterizadas, en un primer momento, por un proceso de autoorganización (Moreno, 2016). Dicha autoorganización hace referencia al despliegue de la autonomía que los mismos participantes en las ferias de trueque ejercen sobre la actividad que están desempeñando, sin la necesidad de un control externo y jerárquico que los dirija. Es un proceso que permite el fluir de las subjetividades a partir de las cuales construir un lugar adaptado a los actores participantes y que haga florecer la creatividad de los mismos.

Esta autoorganización es consustancial a los procesos de aprendizaje de las culturas originarias en las cuales nunca estamos en el caos o en el orden absoluto, sino en un devenir circular entre una y otra característica. Dicho devenir permite la creación de nuevas actividades alejadas de la formalidad y la prescripción, en donde la planificación que intenta ordenar excesivamente no permite el fluir del proceso. El aprendizaje en el intercambio ocurre siempre y cuando se esté dispuesto, consciente o inconscientemente, a hacerlo. La libertad, entonces, es el primer aspecto que determina la autoorganización intencionada en estos espacios. Según Briggs y Peat (1999), los seres humanos nos comportamos creativamente debido a la coherencia existente entre grados de libertad y la autoorganización. El aprendizaje fluye de las ansias de conocer, emerge del mismo proceso emancipativo, lo que permite el fluir de la búsqueda, el intercambio de saberes y la construcción ecológica de esos conocimientos "otros".

\section{DESAPRENDER A TRAVÉS DE LOS SABERES ECOLÓGICOS PRODUCIDOS EN EL INTERCAMBIO}

Convenimos, con Žižek (1998), que el capitalismo global trae adherida la lógica multicultural que incorpora la diferencia a su vez que la neutraliza y vacía de significado, manteniendo así la diferencia colonial. En este devenir urge encaminar proyectos socioeducativos que permitan el entendimiento como acción individual y colectiva en búsqueda de la decolonialidad de la vida, más allá de confabulaciones y estrategias que han llevado a la tergiversación y vaciamiento de proyectos políticos tan necesarios como la interculturalidad y el buen vivir (o küme mongen en mapuzungun): proyectos que con 
el tiempo se han institucionalizados y vueltos funcionales también para los sistemas educativos de Chile y toda Latinoamérica.

"Lo que entiendo como principal desafío es ser auténticamente modernos y conectarnos a la vez con lo más antiguo, para que, a partir de esa contradicción o anacronismo, podamos armar -dentro y fuera de la universidad- una esfera pública inclusiva, democrática e intercultural" (Rivera Cusicanqui, Domingues, Escobar y Leff, 2016, p.4). Sobre esa renovación del pensamiento y articulación con las prácticas comunitarias, populares y colectivas; sobre aquello que ocurre en el espacio fronterizo entre el mundo universitario y su afuera; en definitiva, es sobre los saberes ecológicos a los que se refiere Silvia Rivera Cusicanqui.

En los espacios de trueque de Antofagasta y Valdivia, la relación intercultural y las nociones de buen vivir surgen de manera espontánea; ni lo propio ni lo particular pierde diferencia, se crean nuevas comprensiones, solidaridades y convivencias. La interculturalidad y el anhelo de vivir mejor - que no es otra cosa que vivir con sabiduríase intentan vivir y no forzar; son espacios sociales que no solo promueven condiciones económicas 'otras', sino también saberes y comunicaciones 'otras', saberes ecológicos que en su paso no intentan borrar la memoria ancestral.

En Antofagasta se cruzan las nacionalidades chilena, boliviana, peruana, colombiana y croata, entre otras; sobreviven las culturas ancestrales Aymara y Likan Antay; también dialogan credos religiosos, estudiantes, académicos y trabajadores; se mezclan las edades y los roles; tienen espacios los/as artistas populares y diversas organizaciones socioambientales. "AntofaTrueke" no es la feria que se desarrolla desde, por y en una universidad, hoy es una feria de intercambio y consumo colaborativo de la comunidad, desarrollada para y desde la misma, incluso físicamente comenzó a celebrarse en el Estadio Regional Calvo y Bascuñán de la ciudad de Antofagasta. Mientras que, al sur en Valdivia, la Red Trueke también reapropia las ferias de intercambio como espacio social de las comunidades de la región, y ya casi parece perderse el delgado hilo gestor que un día inició este proyecto educativo transformativo.

El brote de estas dos iniciativas socioeducativas que se han propuesto aprender a desaprender por medio de los saberes ecológicos del trueque trae incorporado una confrontación que puede llegar a debilitar enormemente dichas propuestas en el marco del esfuerzo por un desarrollo más humano; incluso pueden desaparecer o ser anexadas a la racionalidad competitiva del sistema dominante. Sin embargo, también pueden fortalecerse y conquistar grados de autodependencia, e irradiar dicha fuerza solidaria a nuevos segmentos sociales (Max-Neef, 1998), generando condiciones de alteridad que incorporen nuevos aprendizajes; como parece estar ocurriendo -y esperamos continúe- en ambos casos.

\section{CONCLUSIONES. COOPERACIÓN CONTEMPORÁNEA DE ECONOMÍAS LOCALES- REGIONALES EN BASE A COSMOEXISTENCIAS ANCESTRALES}

Las ferias de trueque, al hacer dialogar no solo personas, sino que también territorios, despliegan un escenario fecundo para la reapropiación social y resistencia decolonial, articulado por actores locales que, a través del intercambio y consumo colaborativo, se permiten crear relaciones solidarias de autodependencia en contraposición a la racionalidad 
de la colonialidad y del mercado. El encuentro de modos culturales diversos de ser y estar, con todos los saberes que ello implica, aportan comprensiones y convivencias que resignifican y otorgan nuevo sentido al trueque, ampliando su expresión más allá de lo tangible; potenciando no solo el intercambio de saberes y servicios, sino también un rol educativo de reconexión, revitalización, reapropiación social, reaprendizaje y recuperación de espacios y prácticas locales colectivas.

El desarrollo ecológico y a 'escala humana' que posibilitan los proyectos de trueque tanto de Antofagasta como de Valdivia, socializan una conciencia crítica que va desde la decolonialidad económica hasta intelectual. Aprender a desaprender por medio del txafkintun se presenta como ejercicio decolonial, como intento por decolonizar el propio pensamiento, los imaginarios del ser; y por decolonizar también el saber. La voluntad de apertura y confrontación de los saberes, forma parte del proyecto "AntofaTrueke" como experiencia docente desde la enseñanza y el aprendizaje; que además como praxis trae a la actualidad cotidiana una práctica ancestral que recupera el espacio social de intercambio y consumo colaborativo, y que acoge no solo la diversidad socioeconómica en la ciudad sino también cultural, en un esfuerzo por generar condiciones de alteridad que contribuyan al saber ecológico con nuevos aprendizajes, saberes y toma de conciencia.

Por otro lado, las ferias de trueque en la ciudad de Valdivia surgen en un contexto universitario y de movilización ciudadana, producto del desastre del santuario de la naturaleza Carlos Anwandter el año 2004, tras la contaminación de la planta de celulosa Arauco $^{5}$. Este conflicto socioambiental genera una serie de movimientos de efervescencia social, tales como Acción por Los Cisnes ${ }^{6}$ y el Jardín Agroecológico San Francisco ${ }^{7}$, con actores sociales que ven en el trueque una herramienta de unión que congrega a personas diversas, traspasando barreras generacionales, de género y de clase. Contribuye además en la reivindicación patrimonial de un eje socioeconómico clave para el sur de Chile como fue la antigua estación de trenes, con la realización durante cinco años de la emblemática feria de intercambio "Estación Trueke", como escenario que rememora un medio de transporte

En mayo de 2004, a menos de cuatro meses del inicio de la entrada en operación de la Planta de Celulosa Valdivia, propiedad de Celco, se comenzaría a evidenciar que el Santuario de la Naturaleza Carlos Anwandter era víctima de uno de los desastres ecológicos más emblemáticos de la historia reciente de Chile. La señal más importante del desastre fue dada justamente por la muerte y migración masiva de aves del Santuario: principalmente los cisnes de cuello negro. Del promedio aproximado de 5.000 individuos que existieron en el Santuario el año 2003, según datos de la UACh, a marzo de 2005, solo quedaban 160 y las muertes registradas son aproximadamente 350. Esta cifra excluye a los individuos que pueden haber muerto en las zonas de poca accesibilidad del santuario ( $80 \%$ del humedal), por lo que el total de muertes aumentaría aproximadamente a 1000 . El fenómeno causó alarma pública nacional y detonó la emergencia de un movimiento ciudadano sin precedentes en la ciudad de Valdivia, que exigió explicaciones y medidas preventivas de un daño mayor. Información citada de la página web del Movimiento Acción por los Cisnes (25 de julio de 2017). http://www.accionporloscisnes.org/index.php?option=com_co ntent\&task=blogsection\&id=7\&Itemid=29

6 Acción por los Cisnes es una agrupación ciudadana que surge en Valdivia ante la alarma provocada por la muerte de cisnes de cuello negro y el desastre ecológico que afectó al Santuario de la Naturaleza Carlos Anwandter, en el Río Cruces. Nació el 02 de noviembre de 2004, cuando se realizó la primera asamblea pública de la ciudad para conocer los antecedentes de este desastre ambiental y en la cual se acordaron y organizaron las primeras acciones de denuncia. Información citada de la página web del Movimiento Acción por Los Cisnes (25 de julio de 2017). http://www.accionporloscisnes.org/index. php?option=com_content\&task=blogsection \&id $=5 \&$ Itemid $=27$

7 El Jardín Agroecológico San Francisco fue un espacio lugar abierto a la comunidad que nace el año 2008, entregado en comodato por el Obispado de Valdivia, para dar a conocer y practicar temas de ecología, agricultura orgánica, alimentación saludable, expresión cultural e intercambio de conocimientos. Ubicado a tres cuadras de la plaza de la ciudad de Valdivia, la iniciativa cerró sus puertas el año 2013 al término del comodato. Información citada de su página web (12 de junio de 2017). https://jardinagroecologicosanfrancisco.wordpress.com/que-es-donde-esta/ 
que acercaba territorios y hacía dialogar diversos productos, saberes y servicios. Así, es un evento clave para iniciativas culturales que promueven y fortalecen la identidad local.

Ambas iniciativas han ampliado los límites del trueque. Por medio de experiencias creativas de intercambio notamos que aquello que tenemos, aquello que sabemos y hacemos, puede ser de utilidad para alguien más. La resistencia a la colonialidad por medio de la reciprocidad se encuentra presente en las miles de experiencias de comunicación y participación ciudadana tanto en los txafkintun de Antofagasta como de Valdivia.

Max Neef (1998) defiende el esfuerzo por modificar los currículos de enseñanza en la educación superior, con la idea de que se "incorpore sistemáticamente la reflexión sobre alternativas de desarrollo en sus aspectos propositivos, epistemológicos y metodológicos" (Max-Neef 1998, p. 100). De la integración de conocimientos y experiencias que eviten la tiranía de ideologías reduccionistas pueden brotar proyectos como los que han centrado esta reflexión, que además revitalizan la reapropiación de espacios solidarios de autodependecia humana en su amplio sentido.

La contribución de estos emergentes brotes de saberes ecológicos y encuentro humano no transformarán el estado actual de un hegemónico mercado predador y expansivo, pero sí posibilitarán cosmoexistencias y condiciones de alteridad que permitan nuevas comprensiones y convivencias orientadas a reaprender desde las diversas fisuras que genera la 'modernidad racional' (Walsh, 2015), abriendo de paso espacios educativos e inter-socioculturales 'otros'.

\section{REFERENCIAS BIBLIOGRÁFICAS}

Acosta, A. (2016). O bem viver: uma oportunidade para imaginar outros mundos. São Paulo: Autonomia Literária.

Briggs, J. y Peat, D. (1999). Las siete leyes del caos. Las ventajas de una vida caótica. Grijalbo: Barcelona.

Calvo, C. (2016). Del mapa escolar al territorio educativo: 'disoñando' la escuela desde la educación. $6^{\circ}$ impresión. La Serena: Universidad de La Serena.

De Sousa Santos, B. (2013). Descolonizar el saber, reinventar el poder. Santiago: LOM Ediciones.

De Sousa Santos, B. (13 de noviembre de 2014). La gran división. Diario el Mundo, 13 noviembre. Recuperado de http://www.pagina12.com.ar/diario/elmundo/4-259727-2014-11-13.html

Dussel, E. (2015). Filosofías del sur. Descolonización y transmodernidad. Madrid: Akal.

Fanon, F. (1961). Los condenados de la tierra. Ciudad de México: Fondo de Cultura Económica.

Fanon, F. (2009). Piel negra, máscaras blancas. Madrid, España. Editorial Akal.

Freire, P. (1975). Pedagogía del oprimido. Buenos Aires: Siglo XXI.

Grosfoeguel, R. (2013). Racismo/Sexismo epistémico, universidades occidentalizadas y los cuatro genocidios/epistemicidios del largo siglo XVI. Tabula Rasa, 19, 31-58. doi: https://doi. org/10.25058/20112742.153

Guerrero, P. (2010). Corazonar el sentido de las epistemologías dominantes desde las sabidurías insurgentes, para construir sentidos otros de la existencia (primera parte). Calle 14, Revista de Investigación en el campo del arte. 4(5), 80-95.

Huanacuni, F. (2010). Buen vivir/vivir bien: filosofía, políticas, estrategias y experiencias regionales andinas. Lima: Oxfam América y Solidaridad Suecia América Latina.

Marañón, B. (2014). Buen vivir y descolonialidad: crítica al desarrollo y la racionalidad instrumentales. México: UNAM: Instituto de Investigaciones Económicas, 2014.

Maturana, H. y Dávila, X. (2015). El árbol del vivir. Santiago: MVP Editores. 
Max-Neef, M. (1998). Desarrollo a Escala Humana. Conceptos, aplicaciones y algunas reflexiones. Montevideo: Editorial Nordan Comunidad.

Meleau-Ponty, M. (1945). Fenomenología de la percepción. Barcelona: Planeta Agostini.

Mirón, M. (2004). Oikos y oikonomia: El análisis de las unidades domésticas de producción y reproducción en el estudio de la Economía antigua. Revista Gerión, 22(1), 61-79.

Moreno, A. (2016). Caos y educación: del insípido orden escolar al sabroso caos educativo. Santiago : Ediciones JUNJI.

Neüman, M. (2008). La apropiación social como espacio de negociación con la modernidad. Anuario Ininco, 20(1), 47-78.

Ñanculef, J. (26 de septiembre de 2011). El origen del txafkintun: el mal llamado trueque. Diario ciudadano La Opiñón. Recuperado de: http://www.laopinon.cl/noticia/mapuche/el-origen-deltxafkintun-el-mal-llamado-trueque

Palencia, S., Zamora, M., Salazar, M. y Mendizábal (2014). Del sujeto subalterno al sujeto cosmológico: Un espejo para transformarnos. Cuaderno de Investigación (13). Instituto de Estudios Humanisticos. Guatemala: Ediciones IEHpublica.

Quijano, A. (4 de septiembre de 2009). Colonialidad del Poder y Des/Colonialidad del Poder. Conferencia dictada en el XXVII Congreso de la Asociación Latinoamericana de Sociología.

Quijano, A. (2012). Bien vivir: entre el "desarrollo" y la des/colonialidad del poder. Ecuador Debate. Acerca del Buen Vivir. Quito: Centro Andino de Acción Popular CAAP. 84, 77-87. ISSN: $1012-$ 1498.

Rivera Cusicanqui, S., Domingues, J. Escobar, A. y Leff. E. (2016). Entrevista a Silvia Rivera Cusicanqui: El colonialismo intelectual y los dilemas de la teoría social latinoamericana. Por Maristella Svampa. Cuestiones de Sociología, 14(9), 1-22.

Varela, F., Thompson, E. y Rosch, E. (2011). De cuerpo presente. Las ciencias cognitivas y la experiencia humana. Barcelona: Editorial Gedisa.

Vidal, T. y Pol, E. (2005). La apropiación del espacio: una propuesta teórica para comprender la vinculación entre las personas y los lugares. Anuario de Psicología, 36(3), 281-297.

Walsh, C. (2008). Interculturalidad, plurinacionalidad y decolonialidad: las insurgencias políticoepistémicas de refundar el Estado. Revista Tabula Rasa, 9, 131-152.

Walsh, C. (2010). Interculturalidad crítica y educación intercultural. En Viaña, Tapia y Walsh, Construyendo interculturalidad crítica (pp. 75-95). La Paz: Instituto Internacional de Integración.

Walsh, C. (2015). Conferencia inaugural. I Congreso Internacional: Comunicación, Decolonización y Buen Vivir. Ecuador. Ciespal.

Yáñez-Duamante, C., Browne, R. y Music, A. (2016). Malestar, prensa y ciudadanía en contexto de producción minera al norte de Chile. Chasqui: Revista Latinoamericana de Comunicación, 30, 381-397.

Žižek, S. (1998). Multiculturalismo o la lógica cultural del capitalismo multinacional. En Jameson, F. y Žižek, S. Estudios culturales. Reflexiones sobre el multiculturalismo (pp. 137-188). Barcelona: Paidós. 
